\title{
Determinants of access to improved sanitation facilities in rural districts of southern Ghana: evidence from Dodowa Health and Demographic Surveillance Site
}

\author{
David Etsey Akpakli ${ }^{*}$, Alfred Kwesi Manyeh ${ }^{1,4}$, Jonas Kofi Akpakli ${ }^{3}$, Vida Kukula and Margaret Gyapong ${ }^{1,2}$
}

\begin{abstract}
Objective: Access to improved sanitation facilities is critical to the health and well-being of individuals and communities. However, globally, over 2.5 billion people live without access to safe sanitation facilities and more than $40 \%$ of the world population, do not use a toilet, but defecate in the open or in unsanitary places. In Ghana, only 14\% of the population have access to improved sanitation facilities with great disparities between rural (8\%) and urban (19\%) dwellers. This paper sought to examine the determinants of access to improved sanitation facilities by households among rural dwellers in two districts in southern Ghana.

Results: This study, which involved 16,353 household heads from the Dodowa Health and Demographic Surveillance System, found that sanitation facilities used by households were significantly influenced by age, gender, level of education, occupation, marital and socioeconomic status of household heads. It further revealed that a large proportion (85.94\%) of the study participants did not have access to improved sanitation facilities. The study therefore recommends that the national sanitation laws must strictly be enforced to ensure each household in Ghana has decent and hygienic toilet facility.
\end{abstract}

Keywords: Household head, Improved sanitation, Rural, Ghana

\section{Introduction}

Basic sanitation is considered the lowest-cost technology ensuring hygienic excreta disposal and a clean and healthful living environment both at home and in the neighborhood of users [1]. It involves the use of improved sanitation facilities such as public sewer connection; septic system connection; pour-flush latrine; simple pit latrine; ventilated improved pit latrine and private facilities (sanitation facilities used exclusively by a household) [1]. According to WHO, only private facilities are considered to be improved [2]. The goal of improved sanitation is to hygienically separate human excreta from human contact and therefore reduce exposure to

\footnotetext{
*Correspondence: aderk11@gmail.com

${ }^{1}$ Ghana Health Service/Dodowa Health Research Centre, Dodowa, Ghana

Full list of author information is available at the end of the article
}

fecal contamination [3, 4]. By WHO standards, even an improved facility that is shared by more than one household is considered unimproved $[4,5]$.

Globally, over 2.5 billion people are living without access to safe sanitation facilities which leads to about 200 million tonnes of untreated human excreta annually [6, 7]. About 2.6 billion people, more than $40 \%$ of the world population, do not use toilet facilities, but defecate in the open or in unsanitary places [2]. Access to improved sanitation facilities is a huge challenge in Africa. In Nigeria, over 130 million people, two-thirds of the population, do not have access to adequate sanitation facilities [8] whilst in South Africa about 18 million people also face the same challenge [9]. More than half the population of Ghana (59\%), the highest in the world, depend on shared sanitation facilities including public toilets [10] and about $19 \%$ of Ghanaians practise 
open defecation while $8 \%$ depend on various forms of unimproved sanitation facilities options such as bucket latrines [8].

This paper sought to explore the determinants of access to improved sanitation facilities by households among rural dwellers in the Dodowa Health and Demographic Surveillance area.

\section{Main text \\ Methods \\ Study site and population}

Data for this study was extracted from Dodowa Health and Demographic Surveillance System (DHDSS) which is located in the south-eastern part of Ghana. The operation of the DHDSS can be found elsewhere [10].

The study population comprised household heads (HHs) that were resident in the DHDSS from January 1, 2013 to December 31, 2013.

\section{Outcome and exposure variables}

The outcome variable for this study was type of sanitation facility which is binary and was recorded as 1 "improved" and 0 "unimproved". The unimproved sanitation facilities included open defecation (use of bush or beach), shared pit latrine, own pit latrine and shared ventilated improve pit latrine while the improved sanitation facilities included the use of own ventilated improved pit latrine and flush toilet.

From the available data, seven [7] exposure variables were selected: age, sex, level of education, occupation, marital status, household size and socioeconomic status (wealth index) of the HHs. These exposure variables were selected because from available literature, they have the potential to influence the type of sanitation facilities used by households. The wealth index is a proxy measure of a household's long term standard of living derived through principal component analysis [11].

\section{Statistical analysis}

The extracted data were cleaned to identify all missing values and to check for internal consistency of the responses. Any irregularities in the data were corrected by using the hard copies of the completed questionnaires. Variables were recoded where necessary. The relationship between each exposure variable and outcome variable were explored at the univariate and multivariate level using logistic regression. All analyses were conducted in STATA version 11. The results were presented in the form of tables and summary statistics in odds ratios (OR), with $95 \%$ confidence intervals (CI) and P-values.

\section{Results}

\section{Background characteristics}

Table 1 provides the descriptive information on the socio-demographic characteristics of $16,353 \mathrm{HHs}$ who were included in the study. The median age of the $\mathrm{HHs}$ was 48 years $(\mathrm{IQR}=23)$. The majority $(73.71 \%)$ of the HHs were of the Ga-Dangme ethnic group and $60.46 \%$ were male. A little more than half of $\mathrm{HHs}$ (52.72\%) had junior or senior high school and above level of education while about one-thirds (33.89\%) had no formal education. Of the HHs that were studied, $37.34 \%$ were married whereas $7.94 \%$ were divorced/separated. About two-fifths $(40.84 \%)$ of the $\mathrm{HHs}$ were farmers, while $6.37 \%$ were unemployed. The study found that about one-quarter (26.33\%) had a household size of six and more. The majority of the HHs $(85.94 \%)$ studied used unimproved sanitation facilities.

\section{Bivariate analysis}

From Table 2, 90.98 and $82.63 \%$ of the households headed by females and males used unimproved sanitation facilities, respectively. A total of $34.72 \%$ of $\mathrm{HHs}$ with senior high school and above level of education used improved sanitation facilities while those with junior/middle school education constituting $14.51 \%$ of the study population used improved sanitation facilities. Only 5.88\% households who had no formal education used improved sanitation facilities whilst those with primary level of education constituted $7.77 \%$.

Ninety-nine percent $(99.44 \%)$ of the households in the poorest socioeconomic quintile had unimproved sanitation facilities compared to $68.33 \%$ of the $\mathrm{HHs}$ in the least poor socioeconomic quintile. Statistically, there was an association $(\mathrm{P}<0.05)$ between the variables studied and type of sanitation facility being used except for household size.

\section{Univariate and Multivariate Analysis}

From Table 3, male HHs were more than twice likely to use improved sanitation facilities compared to the female HHs and this was statistically significant. After adjusting for age group, marital status, education, occupation and socioeconomic status, sex of HHs was still associated with type of sanitation facility such that male HHs were 1.23 times more likely to use improved sanitation facilities compared to the female headed households.

Household heads aged 40-44, 45-49, 50-54, 55-59, $60-64,65-59$ years were at least $36 \%$ more likely to use improved sanitation facilities compared to those aged less than 30 years. This was still significant after controlling 
Table 1 Socio-demographic characteristics of the study participants

\begin{tabular}{|c|c|c|}
\hline & Frequency & Percentage (\%) \\
\hline \multicolumn{3}{|l|}{ Age group } \\
\hline$<30$ & 1068 & 6.53 \\
\hline $30-34$ & 1644 & 10.05 \\
\hline $35-39$ & 2046 & 12.51 \\
\hline $40-44$ & 2058 & 12.58 \\
\hline $45-49$ & 1861 & 11.38 \\
\hline $50-54$ & 1806 & 11.04 \\
\hline $55-59$ & 1446 & 8.84 \\
\hline $60-64$ & 1259 & 7.70 \\
\hline $65-69$ & 889 & 5.44 \\
\hline $70+$ & 2276 & 13.92 \\
\hline \multicolumn{3}{|l|}{ Median $=48(\mathrm{IQR}=23)$} \\
\hline \multicolumn{3}{|l|}{ Sex } \\
\hline Female & 6466 & 39.54 \\
\hline Male & 9887 & 60.46 \\
\hline \multicolumn{3}{|l|}{ Ethnicity } \\
\hline Ga-Dangme & 12,054 & 73.71 \\
\hline Akan & 1007 & 6.16 \\
\hline Ewe & 2511 & 15.35 \\
\hline Northern & 675 & 4.13 \\
\hline Others & 106 & 0.65 \\
\hline \multicolumn{3}{|l|}{ Marital status } \\
\hline Single & 1772 & 10.84 \\
\hline Divorced/separated & 1298 & 7.94 \\
\hline Married & 6107 & 37.34 \\
\hline Cohabiting & 5307 & 32.45 \\
\hline Widowed & 1869 & 11.43 \\
\hline \multicolumn{3}{|l|}{ Education } \\
\hline No education & 5542 & 33.89 \\
\hline Primary & 2189 & 13.39 \\
\hline Junior high/middle school & 5886 & 35.99 \\
\hline Senior high school and above & 2736 & 16.73 \\
\hline \multicolumn{3}{|l|}{ Occupation } \\
\hline Unemployed & 1041 & 6.37 \\
\hline Farmer & 6678 & 40.84 \\
\hline Artisan & 2917 & 17.84 \\
\hline Trader & 2987 & 18.27 \\
\hline Civil servant & 1007 & 6.16 \\
\hline Fisherman & 797 & 4.87 \\
\hline Others & 926 & 5.66 \\
\hline \multicolumn{3}{|l|}{ Household size } \\
\hline Less than six & 12,047 & 73.67 \\
\hline Six and above & 4306 & 26.33 \\
\hline \multicolumn{3}{|l|}{ Sanitation (toilet) type } \\
\hline Unimproved & 14,053 & 85.94 \\
\hline Improved & 2300 & 14.06 \\
\hline
\end{tabular}

for sex, marital status, education, occupation and socioeconomic status.

While HHs with primary level of education were 1.35 times more likely to use improved sanitation facilities compared to those with no formal education in the unadjusted model, those with junior high/middle and senior high school and above level of education were 2.72 and 8.51 times more likely to use improved sanitation facilities, respectively compared to those with no formal education. This was statistically significant.

Also, while HHs who were married were 1.42 times more likely to use improved sanitation facilities, those who were divorced/separated, cohabiting and widowed were 22,24 and $35 \%$ less likely to use improved sanitation facilities, respectively compared to those who were single. This was also statistically significant in the unadjusted model. After adjusting, none of them was statistically significant.

Households with more than five members were 1.06 times more likely to use improved sanitation facilities compared to those with less than six members in the unadjusted model and this was statistically not significant.

Civil Servants were 5.15 times more likely to use improved sanitation facilities compared to HHs who were unemployed. This association was significant in both the unadjusted and adjusted models. Artisans and fishermen were 1.52 and 1.63 times more likely to use improved sanitation facilities, respectively compared to $\mathrm{HHs}$ who were unemployed. Farmers and petty traders were 13 and $14 \%$ less likely to use improved sanitation facilities, respectively compared to $\mathrm{HHs}$ who were unemployed.

Household heads with poorer, poor, less poor and least poor socioeconomic status were 4.98, 11.03, 13.38 and 81.69 times more likely to use improved sanitation facilities, respectively compared to HHs from the poorest households. This was still statistically significant after adjusting for other explanatory variables.

\section{Discussion \\ Household demographics}

The age distribution of most HHs (57.57\%) was found to be between 30 and 54 years. This indicates that the $\mathrm{HHs}$ within the study area fell within the economically active group [12]. A large proportion (60.46\%) of HHs were males which reinforces the belief that men generally are considered heads of the family units. Studies by Ridgeway and Smith-Lovin [13], Lewis [14] and Salomone [15] confirmed this assertion [16].

\section{Socio-demographic determinants}

The findings revealed that only $14.06 \%$ of the HHs studied used improved sanitation facilities. This figure agrees 
Table 2 Bivariate analysis of determinants of improved and unimproved sanitation facilities used by households

\begin{tabular}{|c|c|c|c|}
\hline Characteristics of household head & Unimproved n (\%) & Improved n (\%) & $P$ value \\
\hline \multicolumn{4}{|l|}{ Age group } \\
\hline$<30$ & $958(89.70)$ & $110(10.30)$ & \multirow[t]{10}{*}{$<0.001$} \\
\hline $30-34$ & $1473(89.60)$ & $171(10.40)$ & \\
\hline $35-39$ & $1795(87.73)$ & $251(12.27)$ & \\
\hline $40-44$ & $1779(86.44)$ & $279(13.56)$ & \\
\hline $45-49$ & $1562(83.93)$ & $299(16.07)$ & \\
\hline $50-54$ & $1514(83.83)$ & $292(16.17)$ & \\
\hline $55-59$ & $1172(81.05)$ & $274(18.95)$ & \\
\hline $60-64$ & $1057(83.96)$ & $202(16.04)$ & \\
\hline $65-69$ & $725(81.55)$ & $164(18.45)$ & \\
\hline $70+$ & $2018(88.66)$ & $258(11.34)$ & \\
\hline \multicolumn{4}{|l|}{ Sex } \\
\hline Female & $5883(90.98)$ & $583(9.02)$ & \multirow[t]{2}{*}{$<0.001$} \\
\hline Male & $8170(82.63)$ & $1717(17.37)$ & \\
\hline \multicolumn{4}{|l|}{ Ethnicity } \\
\hline Ga-Dangme & $10,741(89.11)$ & $1313(10.89)$ & \multirow[t]{5}{*}{$<0.001$} \\
\hline Akan & $643(63.85)$ & $364(36.15)$ & \\
\hline Ewe & $2029(80.80)$ & $482(19.20)$ & \\
\hline Northern & $5,58(82.80)$ & $117(17.33)$ & \\
\hline Others & $82(77.36)$ & $24(22.64)$ & \\
\hline \multicolumn{4}{|l|}{ Marital status } \\
\hline Single & $1524(86.00)$ & $248(14.00)$ & \multirow[t]{5}{*}{$<0.001$} \\
\hline Divorced/separated & $1151(88.67)$ & $147(11.33)$ & \\
\hline Married & $4963(81.27)$ & $1144(18.73)$ & \\
\hline Cohabiting & $4726(89.05)$ & $581(10.95)$ & \\
\hline Widowed & $1689(90.37)$ & $581(9.63)$ & \\
\hline \multicolumn{4}{|l|}{ Level of education } \\
\hline No education & $5216(94.12)$ & $326(5.88)$ & \multirow[t]{4}{*}{$<0.001$} \\
\hline Primary & $2019(92.23)$ & $170(7.77)$ & \\
\hline Junior high/middle school & $5032(85.49)$ & $854(14.51)$ & \\
\hline Senior high school and above & $1786(65.28)$ & $950(34.72)$ & \\
\hline \multicolumn{4}{|l|}{ Occupation } \\
\hline Unemployment & $925(88.86)$ & $116(11.14)$ & \multirow[t]{7}{*}{$<0.001$} \\
\hline Farmer & $6022(90.18)$ & $656(9.82)$ & \\
\hline Artisan & $2449(83.96)$ & $468(16.04)$ & \\
\hline Trader & $2697(90.29)$ & $290(9.71)$ & \\
\hline Civil servant & $612(60.77)$ & 395 (39.23) & \\
\hline Fisherman & $662(83.06)$ & $135(16.94)$ & \\
\hline Others & $686(74.08)$ & $240(25.92)$ & \\
\hline \multicolumn{4}{|l|}{ Household size } \\
\hline Less than six & $10,377(86.14)$ & $1670(13.86)$ & \multirow[t]{2}{*}{0.213} \\
\hline More than five & $3676(85.37)$ & $630(14.63)$ & \\
\hline \multicolumn{4}{|l|}{ Socioeconomic status } \\
\hline Poorest & 705 (99.44) & $4(0.56)$ & \multirow[t]{5}{*}{$<0.001$} \\
\hline Poorer & $2017(97.25)$ & $57(2.75)$ & \\
\hline Poor & 3325 (94.11) & $208(5.89)$ & \\
\hline Less poor & 4334 (92.94) & $329(7.06)$ & \\
\hline Least poor & 3672 (68.33) & $1702(31.67)$ & \\
\hline
\end{tabular}


Table 3 Unadjusted and adjusted odd ratios of determinants of improved and unimproved sanitation facilities used by households

\begin{tabular}{|c|c|c|c|c|c|c|}
\hline \multirow[t]{2}{*}{ Characteristics } & \multicolumn{3}{|c|}{ Unadjusted } & \multicolumn{3}{|c|}{ Adjusted } \\
\hline & OR & $95 \% \mathrm{Cl}$ & P-value & OR & $95 \% \mathrm{Cl}$ & P-value \\
\hline \multicolumn{7}{|l|}{ Age group } \\
\hline$<30$ & 1.00 & & & 1.00 & & \\
\hline $30-34$ & 1.01 & $0.79-1.30$ & 0.932 & 0.99 & $0.75-1.30$ & 0.938 \\
\hline $35-39$ & 1.22 & $0.96-1.54$ & 0.104 & 1.21 & $0.93-1.58$ & 0.157 \\
\hline $40-44$ & 1.37 & $1.08-1.73$ & 0.009 & 1.60 & $1.22-2.09$ & 0.001 \\
\hline $45-49$ & 1.67 & $1.32-2.10$ & $<0.001$ & 2.01 & $1.53-2.62$ & $<0.001$ \\
\hline $50-54$ & 1.68 & $1.33-2.12$ & $<0.001$ & 2.23 & $1.70-2.93$ & $<0.001$ \\
\hline $55-59$ & 2.04 & $1.61-2.58$ & $<0.001$ & 2.73 & $2.06-3.60$ & $<0.001$ \\
\hline $60-64$ & 1.66 & $1.30-2.13$ & $<0.001$ & 2.71 & $2.02-3.62$ & $<0.001$ \\
\hline $65-69$ & 1.97 & $1.52-2.56$ & $<0.001$ & 3.32 & $2.44-4.51$ & $<0.001$ \\
\hline $70+$ & 1.11 & $0.88-1.41$ & 0.372 & 3.02 & $2.27-4.03$ & $<0.001$ \\
\hline \multicolumn{7}{|l|}{ Sex } \\
\hline Female & 1.00 & & & 1.00 & & \\
\hline Male & 2.12 & $1.92-2.34$ & $<0.001$ & 1.23 & $1.05-1.38$ & 0.008 \\
\hline \multicolumn{7}{|l|}{ Education } \\
\hline No education & 1.00 & & & 1.00 & & \\
\hline Primary & 1.35 & $1.11-1.63$ & 0.002 & 1.28 & $1.04-1.58$ & 0.019 \\
\hline Junior high/middle school & 2.72 & $2.38-3.10$ & $<0.001$ & 1.73 & $1.48-2.03$ & $<0.001$ \\
\hline Senior high school and above & 8.51 & $7.42-9.76$ & $<0.001$ & 3.28 & $2.74-3.91$ & $<0.001$ \\
\hline \multicolumn{7}{|l|}{ Marital status } \\
\hline Single & 1.00 & & & 1.00 & & \\
\hline Divorced/separated & 0.78 & $0.63-0.98$ & 0.029 & 0.97 & $0.75-1.25$ & 0.826 \\
\hline Married & 1.42 & $1.22-1.64$ & $<0.001$ & 1.06 & $1.88-1.27$ & 0.557 \\
\hline Cohabiting & 0.76 & $0.64-0.89$ & 0.001 & 0.85 & $0.71-1.02$ & 0.080 \\
\hline Widowed & 0.65 & $0.53-0.80$ & $<0.001$ & 0.81 & $0.63-1.03$ & 0.090 \\
\hline \multicolumn{7}{|l|}{ Household size } \\
\hline Less than six & 1.00 & & & & & \\
\hline Six and above & 1.06 & $0.96-1.18$ & 0.213 & & & \\
\hline \multicolumn{7}{|l|}{ Occupation } \\
\hline Unemployed & 1.00 & & & 1.00 & & \\
\hline Farmer & 0.87 & $0.70-1.07$ & 0.187 & 0.93 & $0.73-1.17$ & 0.526 \\
\hline Artisan & 1.52 & $1.23-1.89$ & $<0.001$ & 1.05 & $0.82-1.35$ & 0.691 \\
\hline Trader & 0.86 & $0.68-1.08$ & 0.186 & 1.00 & $0.77-1.28$ & 0.983 \\
\hline Civil servant & 5.15 & $4.09-6.48$ & $<0.001$ & 1.57 & $1.21-2.05$ & 0.001 \\
\hline Fisherman & 1.63 & $1.24-2.12$ & $<0.001$ & 1.31 & $0.97-1.77$ & 0.084 \\
\hline Others & 2.79 & $2.19-3.55$ & $<0.001$ & 1.62 & $1.23-1.24$ & 0.001 \\
\hline \multicolumn{7}{|l|}{ Socioeconomic status } \\
\hline Poorest & 1.00 & & & 1.00 & & \\
\hline Poorer & 4.98 & $1.80-13.77$ & 0.002 & 4.91 & $1.77-13.61$ & 0.002 \\
\hline Poor & 11.03 & $4.09-29.75$ & $<0.001$ & 10.66 & $3.94-28.81$ & $<0.001$ \\
\hline Less poor & 13.38 & $4.98-35.98$ & $<0.001$ & 11.40 & $4.23-30.74$ & $<0.001$ \\
\hline Least poor & 81.69 & $30.52-218.64$ & $<0.001$ & 52.44 & $19.52-140.89$ & $<0.001$ \\
\hline
\end{tabular}

with the national figure of $14.00 \%$ [17]. Unimproved sanitation facilities have economic, social, cultural, sex, health, environmental and income effects and to a large extent impede the full realization of human development of the affected persons [16]. Diseases related to poor sanitation and lack of hygiene are some of the most common 
causes of illness and death among the poor of developing countries [18].

Results of our study showed that HHs aged between 40 and 69 years were at least 36\% more likely to use improved sanitation facilities compared to those aged less than 30 years. This could mean that majority of the said category of the study population fall within the economically active group and could afford improved sanitation facilities. A study by Angko revealed similar finding [16].

For sex distribution, the study result showed that male HHs were more than twice likely to use improved sanitation facilities compared to the female HHs. In most societies, women have the primary responsibility for management of household water, sanitation and health. They spend much time on household chores which reinforces time-poverty, disempowers them and lowers their income [19]. In fact this affects the socioeconomic and health conditions of the women in many ways [20].

Further, the findings indicated that the higher the level of education of $\mathrm{HHs}$, the more likely they were to use improved sanitation facilities. This is consistent with a study carried out by Koskei which revealed that educational level of $\mathrm{HH}$ has close relationship with access and use of sanitation facilities [21]. From the findings of this study, about one-thirds of the study population had no formal education. This could explain why majority of them used unimproved sanitation facilities. Nonetheless, these findings contradict the Ghana multiple indicator cluster survey which shows no significant association [22].

For marital status, a study by Koskei revealed similar findings as our study where, most of the married respondents studied, used improved sanitation facilities and only $14 \%$ of those who were separated used improved sanitation facilities. None of the study participants who were single and widowed used improved facilities [21].

\section{Socio-economic determinants}

Civil Servants were more likely to use improved sanitation facilities compared to HHs who were unemployed. Interestingly, our study found that artisans and fishermen were more likely to use improved sanitation facilities whilst farmers and petty traders were less likely to use improved sanitation facilities compared to $\mathrm{HHs}$ who were unemployed. It was also found that access to improved sanitation facilities was mostly determined by the wealth of the households such that the poorer the socioeconomic status of $\mathrm{HHs}$, the less likely it was they would use improved sanitation facilities. According to Boadi and Kuitunen [23], household wealth played a vital role in the acquisition and utilization of improved toilet facilities because of the correlation between household wealth and access to improved well-being [24]. Wealthy households were in a better position to provide improved toilet facilities for their members whilst poor households who were fortunate to have toilet facilities usually shared with other households [24].

This study concludes that age, gender, level of education, occupation, marital and socioeconomic status of HHs are significant determinants of the type of sanitation facilities used and that a large proportion of residents within the study area resort to the use of unimproved sanitation facilities. To meet the Sustainable Development Goal of achieving universal access to improved sanitation facilities and to eliminate open defecation by 2030 , our study recommends that city authorities must strictly enforce the national sanitation laws which state that all households in Ghana must have decent and hygienic toilet facilities in their homes/compounds.

\section{Limitations}

Although this study used a large sample size, its findings are unlikely to be generalized since the HDSS covers only two districts out of the 216 districts in Ghana. Also, other important variables such as culture, traditions, social norms, etc. which could equally have influence on the use of sanitation facility type were not available in the HDSS data.

\section{Abbreviations}

CLTS: Community-Led Total Sanitation; DWD: Dangme West District; DHDSS: Dodowa Health and Demographic Surveillance System; DHRC: Dodowa Health Research Centre; GDHS: Ghana Demographic Health Survey; GHS: Ghana Health Service; GSS: Ghana Statistical Service; INDEPTH: International Network for the Demographic Evaluation of Populations and Their Health; MDG: Millennium Development Goal; MLGRD: Ministry of Local Government and Rural Development; MICS: Multiple Indicator Cluster Survey; UNICEF: United Nations Children's Fund; WHO: World Health Organization.

\section{Authors' contributions}

DEA: Participated in the conceptualization of research idea, conducted literature review and wrote the introductory section. He was also involved in the writing of the results and discussion. AKM: Participated in data extraction, study design and review of manuscript. He also provided statistical analysis support. JKA: Provided statistical analysis, writing and interpretation of results and review of manuscript. VU: Assisted with literature review, review of manuscript and re-shaping of the research topic. MG: Critically reviewed and proof read the entire manuscript. All authors read and approved the final manuscript.

\section{Author details}

${ }^{1}$ Ghana Health Service/Dodowa Health Research Centre, Dodowa, Ghana. ${ }^{2}$ University of Health and Allied Sciences, Ho, Ghana. ${ }^{3}$ Ubora Institute, Accra, Ghana. ${ }^{4}$ School of Public Health, University of the Witwatersrand, Johannesburg, South Africa.

\section{Acknowledgements}

We are grateful to INDEPTH Network for its continuous support to the Dodowa Health and Demographic Surveillance System (DHDSS). We appreciate the hard work and dedication of the field and data management staff of the DHDSS. We also express our profound gratitude to the opinion leaders and residents of the surveillance area for offering their time for interviews and 
for constantly sharing valuable personal information with the DHDSS team over the years.

\section{Competing interests}

The authors declare that they have no competing interests.

\section{Availability of data and materials}

The authors of this paper are unable to make the dataset publicly available due to ethical policies, confidentiality assured study participants and the data sharing policy of the Dodowa Health Research Centre.

\section{Consent for publication}

Not applicable.

\section{Ethics approval and consent to participate}

The set-up of the DHDSS and its data collection procedures have been approved by the Ghana Health Service (GHS) and its Ethical Review Board (ERB). Permission was obtained from management of Dodowa Health Research Centre (DHRC) for the use of this data. Additionally, each respondent was briefed about the HDSS data collection at the beginning of every update round and their consent sought prior to the data collection. Those who refused were excluded. Names and other identifiers of the study participants were not included in the extracted data to ensure confidentiality.

\section{Funding}

The Dodowa Health and Demographic Surveillance System has no core funding. It is supported through ongoing projects at the Dodowa Health Research Centre such as Rectal Artesunate, Malaria Pneumonia Study through WHO/TDR and INDEPTH Effectiveness and Safety Studies (INESS) through the INDEPTH Network.

\section{Publisher's Note}

Springer Nature remains neutral with regard to jurisdictional claims in published maps and institutional affiliations.

Received: 22 December 2017 Accepted: 6 July 2018

Published online: 13 July 2018

\section{References}

1. Progress on drinking water, sanitation and hygiene: 2017 update and SDG baselines. Geneva: World Health Organization (WHO) and the United Nations Children's Fund (UNICEF), 2017. Licence: CC BY-NC-SA 3.0 IGO.

2. WHO/UNICEF. Meeting the MDG drinking water and sanitation target: the urban and rural challenge of the decade. Geneva:WHO Press; 2006.

3. World Health Organization (WHO), United Nations Children's Fund (UNICEF). Progress on sanitation and drinking-water-2013 update. Geneva, Switzerland:WHO Press; 2013.

4. Nelson KB, Karver J, Kullman C, Graham JP. User perceptions of shared sanitation among rural households in Indonesia and Bangladesh. PLoS ONE. 2014;9(8):e103886. https://doi.org/10.1371/journal.pone.0103886.
5. WHO/UNICEF. Progress programme on sanitation and drinking water. New York: WHO/UNICEF; 2010.

6. United Nations Children's Fund (UNICEF). Sanitation and Hygiene -UNICEF promotes safe sanitation for World Water Day 2008. New York: United Nations Children's Fund (UNICEF); 2008

7. WHO/UNICEF. Progress on sanitation and drinking water programme New York: WHO/UNICEF: 2014

8. Obeng PA, Keraita B, Oduro-Kwarteng S, Abaidoo RC, Awuah E, Flemming K. Usage and barriers to use of latrines in a ghanaian peri-urban community. Berlin: Springer International Publishing; 2015.

9. Abdulmalik O, Busari T, Ojo M. Nigeria's sanitation crisis 2016 World Toilet Day Nigeria supplement. Nigeria: WaterAid Nigeria; 2016.

10. Gyapong M, Sarpong D, Awini E, Manyeh KA, Tei DOG, Agyepong IA, et al. Health and demographic surveillance system profile: The Dodowa HDSS. Int J Epidemiol. 2013:42:1686-96.

11. Vyas S, Kumaranayake L. Constructing socio-economic status indices: how to use principal components analysis. Health Policy Plan. 2006:21(6):459-68

12. Ghana Statistical Service (GSS). Ghana living standards survey: report of the fifth round (GLSS 5): 2010 population and housing census report. Accra: Ghana Statistical Service (GSS); 2013.

13. Ridgeway CL, Smith-Lovin L. The gender system in interaction. Annu Rev Sociol. 1999;25:191-216. https://doi.org/10.1146/annurev.soc.25.1.191.

14. Lewis J. Gender and the development of welfare regimes. J Eur Social Policy. 1992;3:159-73.

15. Salomone RC. Feminist voices in the debate over single-sex schooling: finding common ground. Michigan J Gender Law. 2004;11:63-95.

16. Angko W. Household access to safe and improved drinking water and basic sanitation in Wa municipality. Eur J Bus Manag. 2013;5:23.

17. WHO and UNICEF. Joint Monitoring Programme (JMP). Progress on sanitation and drinking-water: 2014 update. Geneva:WHO and UNICEF; 2014.

18. Bartram J, Lewis K, Lenton R, Wright A. Focusing on improved water and sanitation for health. Lancet. 2005;365:810-2.

19. UNDP. Human development report 2006: beyond scarcity: power, poverty and global water crisis. New York: UNDP; 2006.

20. Ghebremedhin Y. Effects of insufficient water supply and sanitation. In: 25th WEDC conference. Addis Ababa, Ethiopia; 1999.

21. Koskei EC, Koskei RC, Koske MC, Koech HK. Effect of socio-economic factors on access to improved water sources and basic sanitation in bomet municipality, Kenya. Res J Environ Earth Sci. 2013;5(12):714-9.

22. Ghana Statistical Service. Ghana multiple indicator cluster survey with an enhanced malaria module and biomarker: final report. Accra: Ghana Statistical Service; 2011.

23. Boadi $\mathrm{KO}$, Kuitunen M. Environment, wealth, inequality and the burden of disease in the Accra metropolitan area, Ghana. Int J Environ Health Res. 2005;15(3):193-206.

24. Ayesu E, Owusu ES, Asante C. Household characteristics and utilization of toilet facilities in Ghana: a multinomial logistic approach. Int I Innovative Res Dev 2015;4(9).

\footnotetext{
Ready to submit your research? Choose BMC and benefit from:

- fast, convenient online submission

- thorough peer review by experienced researchers in your field

- rapid publication on acceptance

- support for research data, including large and complex data types

- gold Open Access which fosters wider collaboration and increased citations

- maximum visibility for your research: over 100M website views per year
}

At BMC, research is always in progress.

Learn more biomedcentral.com/submissions 